\title{
KNOWLEDGE, ATTITUDES AND COVID-19-RELATED BEHAVIOR AMONG INDIVIDUALS AGED 50 AND OLDER IN LATVIA
}

\author{
Ilona Gehtmane-Hofmane \\ Riga Stradins University, Latvia \\ Madara Teraudkalna \\ Riga Stradins University, Latvia \\ Olga Rajevska \\ Riga Stradins University, Latvia \\ Ilze Koroleva \\ University of Latvia, Latvia \\ Ieva Reine \\ Riga Stradins University, Latvia
}

\begin{abstract}
The coronavirus disease 2019 (COVID-19) was declared a pandemic by the WHO on March 11, 2020, due to its high infection rate, which caused thousands of deaths worldwide and expanding. The evolving outbreak of COVID-19 requires health-protective behavior that can alleviate the severity of an epidemic. Therefore, recognizing the underlying drivers of health-protective behavior against COVID-19 is urgently needed to form policy responses. The purpose of this study was to investigate the individual-level underlying drivers affecting the formation of knowledge, attitudes, and COVID-19-related health-protective behavior among individuals aged 50 and older who are more vulnerable to complications of infection because of their age. The factors making individuals more vulnerable are also associated with the ability to access and understand information, make well-informed decisions, and take health-protective and promoting actions, especially when information itself is not timely, trusted, consistent, or actionable. The researchers used data from a representative population sample consisting of 50-80-year-old individuals, obtained from indepth, semi-structured telephone interviews during July - August 2020, between the first and second waves of COVID-19. For conducting qualitative data analyses, the Grounded Theory (GT) approach for developing code structure was used.
\end{abstract}

Keywords: Attitudes, COVID-19, Grounded Theory Approach, health literacy, healthprotective behavior, knowledge. 


\section{Introduction}

COVID-19 was announced by the World Health Organization as a global pandemic on March 11, 2020. On March 12, 2020, an emergency situation was declared in Latvia, and related restrictions to reduce the prevalence of infection were introduced.

The evolving outbreak of COVID-19 requires health-protective behavior that can help to alleviate the severity of an epidemic. Therefore, recognizing the underlying drivers of health-protective behavior against COVID-19 on individual level is urgently needed to form policy responses in the future.

The existing literature indicates that the knowledge and attitudes of the people toward COVID-19 are critical for promoting effective infection restrictive measures adopted in a country. It is noted that knowledge is the most significant driver for attitude formation that results in health-protective behavior. However, health-protective behavior itself is strongly shaped by socioeconomic status gradients. Socioeconomic status (SES) usually is assessed by determining education, income, and occupation, and/or a combination of these determinants. In health studies, the interrelation between these SES measures was the most substantial and most consistent for health-protective behavior. However, SES determinants as single measures are not always sufficient (Bish \& Michie, 2010; Pampel, Krueger \& Denney, 2010; Dupas, 2011; Chavarría et al., 2020).

The purpose of this study was to investigate the individual-level underlying drivers affecting the formation of knowledge, attitudes, and COVID-19-related health-protective behavior among individuals aged 50 and older who are more vulnerable to complications of infection because of their age.

The researchers used data from a representative population sample consisting of 50-80-year-old individuals, obtained from in-depth telephone interviews during July - August 2020 between the first and second waves of COVID-19.

For conducting and evaluating analyses of qualitative data applicable for the aim of this research, the Grounded Theory Approach was used.

\section{Literature Review}

The existing literature indicates that knowledge and attitude significantly correlated with risk perception regarding infectious diseases and healthprotective behavior. Both the prevention and control of spread of infectious diseases can be positively affected by health-protective behavior of the general population as well as of people in risk groups. (Brewer et al., 2007; Zwart et al., 2009; Savadori \& Lauriola, 2021). 
Epidemics are usually followed by fear. Health-protective behavior toward infectious diseases is often associated with substantial fear and anxiety in the general population or specific communities, especially when morbidity and mortality rates are relatively high. The pressure caused by physical distancing resulting in lack of contact with family or friends, in fear of going out, the compulsive need to hoard food and essentials or medical supplies, and stigma toward people with symptoms of coronavirus infection are the possible experiences of people during a pandemic (Tognotti, 2013; Riva, Benedetti \& Cesana, 2014; Savadori et al., 2021).

However, the use of fear-creating tactics in public health messages about pandemics to promote the formation of health-protective behavior among the population is widely discussed. This interrelation could be summarized into two opposite by nature perspectives: 1) fear among the people could further complicate the measures taken to prevent the spread of the disease; 2) threatening health messages about infectious diseases producing fear among the population could be effective to prevent the spread of the disease. It is noted that social media have high power to produce misinformation in emergency communication during times of crisis to manage public outreach. This can confuse individuals and they may become more doubtful with regard to any type of information they access. Fear makes individuals more vulnerable and is also associated with reduced ability to access and understand information, make well-informed decisions and choices for the construction of health-protective behavior, as well as to take health-promoting actions (Person et al., 2004; Simpson, 2017; Fairchild et al., 2018; Ornell, Schuch, Sordi \& Kessler, 2020; Zarocostas, 2020). This is a set of skills commonly called health literacy.

Health literacy concerns the knowledge, skills, and attitudes of persons to obtain, process, understand information, make well-informed choices and decisions to develop health-protective behavior. Although the importance of health literacy in the population is increasingly recognized, there is no consensus on the definition of this term and its conceptual dimensions. Therefore, the possibilities of measurements and comparisons are limited. Since the emergence of the COVID-19 pandemic and related public health dilemmas, like healthprotective behavior, the issue of health literacy was little discussed. Health literacy was reported to be underestimated in the COVID-19 crisis. Health literacy among the population - knowledge, skills, and attitudes - is essential for the prevention of the disease, as well as dealing with situations requiring a rapid reaction (Sorensen et al., 2012; Sorensen et al., 2015; Abdel-Latif, 2020; Abel \& McQueen, 2020; Paakkari \& Okan, 2020). Older people are a group which most likely possess lower health literacy than population in general and at some point 
they need help in navigating, understanding, or acting according to sometimes quite complex and contradictory information.

\section{Methodology}

To gain a more detailed and profound understanding of the topic of this study, the in-depth semi-structured interview was developed with the aim to understand true meanings that individuals assign to the complexity of their attitudes, behaviors, and experiences.

The in-depth semi-structured interview consisted of 6 sections: 1) personal experience with Covid-19;2) use of health and social care services; 3 ) emotional well-being during the pandemic; 4) use of information and communications technology tools during the pandemic; 5) assessment of government action and attitudes towards repatriation issues during the pandemic; 6) notion about COVID-19. The sociodemographic variables included age, gender, level of education, residential location, and occupation.

In the context of the raised research question, qualitative data from the questions included in the thematic blocks 4 and 6 were analyzed.

There were five (5) items in Section 4: questions about whether and how the habits of using information and communication tools and channels changed during the pandemic and questions about the sources of information related to COVID-19.

There were eight (8) items in Section 6: questions concerning respondents knowledge and attitudes towards COVID-19 (sources of infection, fear of disease, population groups at risk of infection, danger and origin of the virus, effectiveness and barriers to the introduced restrictive measures, attitudes towards information provided by the government and public authorities concerning COVID-19), the losses and benefits of the pandemic, the effectiveness of reducing the spread of the virus by using masks and observing physical distancing, the reliability of the information, and sources of information they rely on.

The Grounded Theory approach was used in the data analysis offering a systematic process of qualitative data coding. In this approach, coding of one data element (statement), continuous comparison, and opposition to all other (similar or different) elements (statements) was done to develop a theoretical substantiation for a possible relationship between different data elements. To emphasize an integrated view of the data and their specific contexts, the researchers used both Grounded Theory approach of data analysis, inductive and deductive, by employing predetermined codes to guide data analysis and 
interpretation. In the initial stage of coding, the researchers conceptualized fragments (statements) of the data obtained in the interviews, from which the categories describing the research topics were distinguished, and the theoretical links between the categories were determined (Charmaz, 2006; Corbin \& Strauss, 2011; Chamberlain-Salaun, Mills \& Usher, 2013).

Age diversity, gender diversity, geographical diversity was observed when selecting the respondents.

Sixteen (16) respondents participated in the interview, 10 of them with higher education. Among respondents, there were both men and women from various cities of Latvia, including small-town residents and rural residents. Respondents represented 50-80-year-old individuals.

The respondents were fully informed about the purpose, methods, and possible uses of the research, as well as what their participation involves. Involvement of the research participants was voluntary. All the research participants were given information explaining the purpose of the research, the process of record-keeping, and how the data will be used. For the interviewees, precise information on the purpose of the study was repeated verbally at the time of the interview. Consent was recorded.

\section{Research Results}

Information and communications technologies are used on a daily basis by all respondents, regardless of their age, education, employment status, and place of residence (urban or rural), both for communication and obtaining information. Smart devices are not used by respondents due to visual impairments and technological limitations (e.g., they do not have a smartphone).

A large proportion of the respondents consider that the highest risk of becoming infected with Covid-19 is associated with people coming from abroad. Examples of their statements:

- "...well, just from what I've heard on TV that when contacting with people who have been abroad recently...";

- "...if we so look at the news now, then all these patients, they have infected just when the virus is brought from somewhere. This is exactly that people come in, especially on planes, that there are people from all over the world, sitting in a plane, then someone gets infected, they will infect each other...".

Respondents believe that there is also a high risk of infection in public places and from strangers. However, none of the respondents indicate possible infection from people they know or from their family members. Examples of their statements: 
- "...indoors, at an event, and where you don't know where all the people are from...";

- "...less risk at private events...At a normal party, we all know where we all come from...".

Several respondents pointed out that the mass media purposefully cultivates fear among the population, which can lead to stress amplification and thus has a negative effect on immunity and increases the risk of infection. In their view, the information provided by the media and government officials is disproportionate to the seriousness of the situation and tends to intimidate people. Examples of their statements:

- "...the highest risk, I think, is by watching our media. This is the greatest risk of infection...And, by the way, what is done with us today is intimidation with this disease. And the more scared a person is, the more is the possibility of the disease, much greater...";

- "...it is not normal, a person must be afraid all the time... a person gets sick just because he has to be afraid of his ailments all the time...".

When comparing and opposing the data obtained during the interviews on whether the respondents are afraid of getting sick with COVID-19, it was found that those respondents who believe that the media purposefully intimidate people are not scared of getting sick. Examples of their statements:

- "...I don't think I should be so afraid of it all, because if I start to get scared, then maybe it will infect me. It is usually said that if you are not afraid, then it doesn't infect, that the disease is afraid of those who are not afraid...";

- "...I have no fear at all...The risk of getting sick, if you think about the illness, you will definitely get sick...”.

In addition, those who believe that the media purposefully intimidate people think that... (examples of their statements):

- "...with the test, the virus can be put inside you to get sick. Also, with the help of $5 G$ radiation, at which point to turn on and isolate you...”;

- "...if a vaccine is administered to you, then virus runs inside you...".

Respondents who do not identify themselves in the risk group are not afraid to get sick. Examples of their statements:

- "...higher risk of illness ...for riders around the world, travelers...";

- "...for doctors, salespersons and cleaners, all service personnel...";

- "...seems to be dangerous for the elderly...";

- "...for those who have some problems, some already chronic ailments, well, they are at risk...";

- "...those who toss around, well, who wander everywhere, who pile up, so to speak...Well, retirees, though, don't organize any parties...". 
Also, respondents who believe that COVID-19 is not dangerous are not afraid of getting sick. Examples of their statements:

- “...no, I don't, ... this covid, though, does not correspond to any pandemic or epidemic...there is some kind of flu... covid analyses have been collected from me five times... and it is not, it is not, it is not here. It is not coming...".

Significantly, those who identify themselves at risk and who are at higher risk of developing the disease, are not afraid of falling ill. Examples of their statements:

- "...I had no fear and neither do I now, because, as I said, I am 77, I have lived a good life, I have two good daughters and four grandchildren and, after all, why should I be afraid, if it is destined, then it will be destined, if not, then no...";

- "...at my age, there is nothing to be afraid of. It is already lived...".

Respondents point out that the physical distancing could reduce the spread of the disease. At the same time, most respondents acknowledging the usefulness of the physical distancing in limiting the spread of the infection consider the use of masks to be ineffective.

Respondents also point to various problems creating obstacles to the observance and implementation of the physical distancing: 1) irresponsibility and selfishness of people; 2) practical issues, such as little space in public transport to maintain the necessary distance from each other. Examples of their statements:

- "...either himself or someone else does not observe distancing...";

- "...people, however, should not laugh nor about two meters, nor hand disinfectants, neither hand washing, but they should do it...";

- "...during any virus, one should not sneak, as our people are used to do, even standing in line at the cash register to step on other's back, should not, you should observe everything, we have enough space in supermarkets, we have to observe that distance...".

Most respondents express distrust in their statements regarding the information provided by the government and public authorities on the disease and its prevalence. Examples of their statements:

- "...there is a feeling that no one really knows. Trust in all of them is being lost... Our government, in general, is seemingly repeating what is being said, for example, there in some America or Europe, in Brussels...";

- "...very minimal credibility....one moment someone says something you might believe, the next moment he maybe says already something else...";

- "...yes, I believe somewhere a little bit, well, but I'm letting pass a lot, and I'm sad in the sense that I can't believe them..."; 
- "...I do not trust anyone 100\%, because they definitely present information, as they, let's say, think, purely subjective, express the objective part subjectively. Maybe default something, distort something, well, but the question is for what purpose they are doing it...".

\section{Discussion}

Analysis of the qualitative data, obtained from in-depth, semi-structured telephone interviews with 50-80-years-old individuals during July - August 2020 between the first and second waves of COVID-19, showed that at individual-level underlining drivers affecting the formation of knowledge, attitudes against COVID-19, and health-protective behavior could be categorized into three main groups: 1) health-literacy; 2) life-experience; 3) selfperception.

At the individual level, health-protective behavior does not directly depend on socioeconomic status gradients - education, income, and occupation (Bish \& Michie, 2010; Pampel et al., 2010; Dupas, 2011; Chavarría et al., 2020). Low health literacy among the population may cause obstacles in understanding or acting according to important and sometimes quite complex and contradictory information, as well as observing the precautionary procedures and national measures.

Health-protective behavior resulting in positive outcomes during a crisis depends directly on everyone's health-literacy level and can have an important role in both the prevention and control of spread of infectious diseases. The existing literature indicates that knowledge and attitude significantly correlated with the risk perception regarding infectious diseases and health-protective behavior (Brewer et al., 2007; Zwart et al., 2009; Savadori \& Lauriola, 2021).

Social media have high power to produce misinformation in emergency communication during times of crisis to manage public outreach. Health-literacy increases the ability to access and understand information, make well-informed decisions, and take health-protective and promoting actions, especially when information itself is not timely, trusted, consistent, or actionable (Person et al., 2004; Simpson, 2017; Fairchild et al., 2018; Ornell et al., 2020; Zarocostas, 2020). Health literacy among the population - knowledge, skills, and attitudes is essential for the prevention of the disease, as well as responding to the disease in situations where a rapid reaction is needed. 


\section{Conclusions}

The development of health-literacy should become essential in order to ensure individuals and societies preparedness for emergency (and not only for emergency) situations, such as the COVID-19 pandemic. Nations' investment in the health literacy of its citizens could help to reduce the spread of the infection and understand the basis behind the social responsibility and disease prevention. The outcome of this study highlighted a growing need to develop and implement innovative local strategies and educational interventions to improve health literacy and awareness among the older population related to COVID-19 and its preventive practices in order to meet its elimination goals.

\section{Acknowledgments}

The study was performed within the project "Impact of Covid-19 on aging populations in Latvia: recommendations for mitigation health and social effects and preparedness for potential crises in the future" in the framework of VPPCOVID-2020/1-0011 "Impact of COVID-19 on health care system and public health in Latvia; ways in preparing health sector for future epidemics".

\section{References}

Abdel-Latif, M. M. M. (2020). The enigma of health literacy and COVID-19 pandemic. Public Health, 185, 95-96. DOI: https://doi.org/10.1016/j.puhe.2020.06.030

Abel, T., \& McQueen, D. (2020). Critical health literacy in pandemics: the special case of COVID-19. Health Promotion International. DOI: https://doi.org/10.1093/heapro/daaa141

Bish, A., \& Michie, S. (2010). Demographic and attitudinal determinants of protective behaviours during a pandemic: A review. British Journal of Health Psychology, 15(4), 797-824. DOI: https://doi.org/10.1348/135910710X485826

Brewer, N. T., Chapman, G. B., Gibbons, F. X., Gerrard, M., McCaul, K. D., \& Weinstein, N. D. (2007). Meta-analysis of the relationship between risk perception and health behavior: The example of vaccination. Health Psychology, 26(2), 136-145. DOI: https://doi.org/10.1037/0278-6133.26.2.136

Chamberlain-Salaun, J., Mills, J., \& Usher, K. (2013). Linking symbolic interactionism and grounded theory methods in a research design: from Corbin and Strauss' assumptions to action. SAGE Open. https://doi.org/10.1177/2158244013505757

Charmaz, K. (2006). Constructing grounded theory: a practical guide through qualitative analysis. Thousand Oaks, CA: SAGE. Retrieved from https://books.google.lv/books?hl=lv\&lr=\&id=2ThdBAAAQBAJ\&oi=fnd\&pg=PP1\&ots $=\mathrm{f} \_\mathrm{j}$ V7H1BxU\&sig $=\mathrm{RLKSpitGFBwxu81LsEamuESYexI \& redir}$ esc $=\mathrm{y} \# \mathrm{v}=$ onepage\&q\& $\mathrm{f}=$ false 
Chavarría, E., Diba, F., Marcus Marthoenis, M. E., Reuter A., Rogge, L., \& Vollmer, S. (2020). Knowing versus doing: Protective health behavior against COVID-19 in Indonesia. Georg-August Universität Göttingen, Courant Research Centre - Poverty, Equity and Growth (CRC-PEG),

Göttingen Discussion Papers. (n.d.). No. 273, Datafile. Retrieved from https://www.econstor.eu/bitstream/10419/219320/1/1700639986.pdf

Corbin, J. M., \& Strauss, A. L. (2008). Basics of qualitative research: techniques and procedures for developing grounded theory. $3 \mathrm{rd}$ ed. Thousand Oaks, $\quad$ CA: SAGE. Retrieved from https://books.google.lv/books?hl=lv\&lr=\&id=hZ6kBQAAQBAJ\&oi=fnd\&pg=PP1\&ots $=6 \mathrm{jL} 8 \mathrm{Mu} 9 \mathrm{EV}-$

\&sig=o9DXF_y7FuH5vyNDG6vhKq9YVY\&redir_esc $=\mathrm{y} \# \mathrm{v}=$ onepage \&q\&f $=$ false

Dupas, P. (2011). Health Behavior in Developing Countries. Annual Review of Economics, 3, 425-449. DOI: https://doi.org/10.1146/annurev-economics-111809-125029

Fairchild, A.L., Bayer R., Green, S.H., Colgrove J., Kilgore E., Sweeney M., \& Varma, J.K. (2018). The Two Faces of Fear: A History of Hard-Hitting Public Health Campaigns Against Tobacco and AIDS. American Journal of Public Health, 108, 1180-1186. DOI: https://doi.org/10.2105/AJPH.2018.304516

Ornell, F., Schuch, J.B., Sordi, A. O., \& Kessler, F. H. P. (2020). "Pandemic fear"and COVID-19: mental health burden and strategies. Brazilian Journal of Psychiatry, 42(3). DOI: https://doi.org/10.1590/1516-4446-2020-0008

Paakkari, L., \& Okan, O. (2020). COVID-19: health literacy is an underestimated problem. The Lancet Public Health, 5(5), 249-250. DOI: https://doi.org/10.1016/S24682667(20)30086-4

Pampel, F. C., Krueger, P.M., \& Denney, J.T. (2010). Socioeconomic Disparities in Health Behaviors. Annual Review of Sociology, 36, 349-370. DOI: https://doi.org/10.1146/annurev.soc.012809.102529

Person, B., Sy, F., Holton, K., Govert, B., Liang, A., Garza, B., \& Zauderer, L. (2004). Fear and Stigma: The Epidemic within the SARS Outbreak. Emerging Infectious Diseases, 10(2), 358-363. DOI: https://dx.doi.org/10.3201/eid1002.030750

Riva, M., Benedetti, M., \& Cesana, G. (2014). Pandemic Fear and Literature: Observations from Jack London's The Scarlet Plague. Emerging Infectious Diseases, 20(10), 1753 1757. DOI: https://dx.doi.org/10.3201/eid2010.130278

Savadori, L., \& Lauriola, M. (2021). Risk Perception and Protective Behaviors During the Rise of the COVID-19 Outbreak in Italy. Frontiers in Psychology. DOI: https://doi.org/10.3389/fpsyg.2020.577331

Simpson, J. K. (2017). Appeal to fear in health care: appropriate or inappropriate? Chiropractic \& Manual Therapies, 25(27). DOI: https://doi.org/10.1186/s12998-0170157-8

Sorensen, K., Pelikan J. M., Röthlin F., Ganahl k., Slonska Z., Doyle G., Fullam J., Kondilis B., Agrafiotis D., Uiters E., Falcon M., Mensing M., Tchamov K., van den Broucke, S., \& Brand, H. (2015). Health literacy in Europe: comparative results of the European health literacy survey (HLS-EU). European Journal of Public Health, 25(6), 10531058. DOI: https://doi.org/10.1093/eurpub/ckv043

Sorensen, K., Van den Broucke, S., Fullam, J., Doyle, G., Pelikan, J., Slonska, Z., \& Brand, H. (2012). Health literacy and public health: A systematic review and integration of 
definitions and models. BMC Public Health, 12(80). DOI: https://doi.org/10.1186/14712458-12-80

Tognotti, E. (2013). Lessons from the History of Quarantine, from Plague to Influenza A. Emerging Infectious Diseases, 19(2), 254-259. DOI: https://dx.doi.org/10.3201/eid1902.120312

Zarocostas, J. (2020). How to fight an infodemic. The Lancet Public Health. World report, 395(10225), 676. DOI: https://doi.org/10.1016/S0140-6736(20)30461-X

Zwart, O., Veldhuijzen, I.K., Elam, G., Aro, A.R., Abraham T., Bishop, G. D., Voeten, H. A. C. M., Richardus, J.H., \& Brug, J. (2009). Perceived Threat, Risk Perception, and Efficacy Beliefs Related to SARS and Other (Emerging) Infectious Diseases: Results of an International Survey. International Journal of Behavior Medicine, 16, 30-40. DOI: https://doi.org/10.1007/s12529-008-9008-2 